\title{
0.12\% Chlorhexidine Effectively Prevents Plaque Accumulation Rate and Early Signs of Gingivitis: A Split Mouth, Double Blind, Placebo Controlled and Parallel Study E Cifcibasi ${ }^{1}$, E Bozbay $^{2,3}, \mathrm{CZ}_{\text {Koyuncuoglu}}^{2}, \mathrm{~S} \mathrm{Ozel}^{4}, \mathrm{~S} \mathrm{Cintan}^{1}$
}

\begin{abstract}
Background: The aim of this split-mouth study was to compare the antiplaque and antigingivitis efficacy of different chlorhexidine (Chx) formulations and essential oils (EO) over negative control (steril saline) during the first 4-day of plaque accumulation on cleaned tooth surfaces.

Subjects and methods: Systemically and periodontally healthy dental students were enrolled. After supragingival prophylaxis, subjects were advised to refrain from oral hygiene measures. Two test; 0.12\% Chx (Klorheks $\left.{ }^{\circledR}\right), 0.1 \%$ Chx $\left(\right.$ Eludryl $\left.^{\circledR}\right)$, one positive control; EO (Listerine ${ }^{\circledR}$ Total Care) one negative control (sterile saline) agents were used for supragingival irrigation by the clinician. Plaque index $(\mathrm{PI})$, gingival index $(\mathrm{GI})$, bleeding on probing $(\mathrm{BoP})$, periodontal probing depth $(\mathrm{PPD})$ were recorded at 1 and 5 days of the study.

Results: Plaque scores were significantly higher at 5 days compared to 1 st day for each agent $(\mathrm{p}<0.05)$. Both $\mathrm{Chx}$ formulations resulted in lower plaque scores compared to saline $(\mathrm{p}<0.05)$. Accumulated plaque quantity at the end of 4 days was significanly lowered only in $0.12 \% \mathrm{Chx}$ applied quadrants than the control agent $(\mathrm{p}<0.05) .0 .12 \% \mathrm{Chx}$ significantly prevented gingival inflammation compared to saline $(\mathrm{p}<0.05)$.
\end{abstract}

Conclusions: The results of this study suggest that $0.12 \% \mathrm{Chx}$ concentration effectively prevents plaque accumulation and early signs of gingivitis significantly better than $0.1 \% \mathrm{Chx}$ with alcohol and EO in absence of regular plaque control.

Keywords: Chlorhexidine, dental plaque, essential oil

From: ${ }^{1}$ Department of Periodontology, Faculty of Dentistry, Istanbul University, ${ }^{2}$ Department of Periodontology, Faculty of Dentistry, Istanbul Aydin University, ${ }^{3}$ Department of Odontostomatologic and Maxillofacial Sciences, Sapienza University of Rome, Italy and ${ }^{4}$ Department of Bioistatistics, Faculty of Medicine, Istanbul University, Istanbul, Turkey. Department of Odontostomatologic and Maxillofacial Sciences, Sapienza University of Rome, Italy.

Correspondence: Dr CZ Koyuncuoglu, Department of Periodontology, Faculty of Dentistry, Istanbul Aydin University, Beşyol Mah. İnönü Cad. Akasya Sk. No: 6 Küçükçekmece, Istanbul, Turkey.

E-mail: zekikoyuncuoglu@aydin.edu.tr 


\section{INTRODUCTION}

Dental plaque, currently known as dental biofilm, is responsible for the initiation of periodontal disease and tooth decay. Dental plaque biofilm first starts as a pellicle, a protein film that forms on the surface of enamel by selective binding of salivary glycoproteins (1). The pellicle forms in seconds after meachnsical cleaning of a tooth. It protects the tooth from acid attacks, which cause erosion of enamel tissue. The first bacteria to attach to the pellicle are gram-positive aerobic cocci such as Streptococcus sanguinis. These bacteria can replicate in the aerobic (rich in oxygen) environment of the oral cavity and form micro-colonies within minutes after attachment. Other bacteria including Streptococcus mutans can grow in these colonies. After only a few days, anaerobic gram-negative cocci, rods, and filaments begin to colonise the plaque; they are responsible for the initiation of gingivitis and periodontitis. Studies have established that the ability to control the onset or progression of periodontal diseases is clearly improved by regular plaque control (2).

Mechanical plaque control efforts have some limitations as home care as they require adequate manual dexterity, adequate time, and a definite motivation. Because of these limitations, chemical plaque control agents have been advocated to assist mechanical plaque removal efforts. Regular assistance from these agents is recommended by some researchers (4-6). Bisbiguanides (chlorhexidine, Chx) have been found to have a more pronounced antiplaque and anti-gingivitis effect compared to other agents $(4,6)$. Chx has been included in mouthrinses at various concentrations and in different formulation (7). A $0.2 \%$ concentration of this agent is considered the gold standard $(7,8)$. In a recent review, Chx $0.12 \%$ mouthrinse was compared with $\mathrm{Chx} 0.2 \%$, and the latter was reported to show a small but significant difference in plaque inhibition (9). However, no differences have been shown in anti-plaque efficacy between $0.1 \%, 0.12 \%$, and $0.2 \% \mathrm{Chx}$ mouthrinses in long-term clinical studies (10, 11). In addition, plaque inhibition by Chx was found to be dependent on dose more than 
concentration $(6,12)$. Chx has no known systemic toxicity, and supra infection and microbial resistance do not occur (7). Common side effects of chlorhexidine, such as tooth staining and taste perturbation, limit long-term use of the agent $(14,15)$.

Alcohol is generally used as a chemical ingredient in mouthrinse solutions. Alcohol is used 1) as a vehicle to dissolve other ingredients, 2) to protect the stability and activity of the formulation, and 3$)$ as an antiseptic agent $(7,13,16)$. However, alcohol addition is one of the most controversial issues about Chx formulations (17-19). Its presence might be responsible for an increased risk of oral cancers $(17,18)$. It has been advised that alcohol should not be used in certain patient groups, such as those who have mucositis, have undergone from headand-neck irradiation, are immunocompromised, or are alcoholics (19) Comparative studies evaluating the effectiveness of mouthrinses with and without alcohol have reported conflicting results $(7,20)$. In a recent study, it was concluded that the benefit of alcohol in mouthrinses is negligible, and since alcohol may carry a risk of oral cancer, mouthrinses that contain alcohol should not be recommended (13).

The effectiveness of essential oil (EO) mouthrinses in controlling plaque and gingivitis has been demonstrated in long- and short-term clinical studies (21-24) and EOs have anti-plaque effects comparable to those of Chx (25-28). EO was also reported to have an additional effect when used for subgingival irrigation of deep residual periodontal pockets (29). However, there are substantial data reporting $\mathrm{Chx}$ to be superior to $\mathrm{EO}(21,30,31)$.

The aim of this clinical study was to compare the clinical efficacy of commercially available mouthrinses containing $0.1 \% \mathrm{Chx}$ with alcohol and $0.12 \% \mathrm{Chx}$ in an alcohol-free formulation to positive (EO) and negative (sterile saline) controls in dental students in a 4-day non-brushing model. The other aims of the study were to evaluate patient compliance with the guidelines of a questionnaire and any possible side effects of the test agents. 


\section{SUBJECTS AND METHODS}

\section{Study population}

The study was conducted at the Faculty of Dentistry, Department of Periodontology, and the study protocol was approved by the regional Ethics Committee. All subjects were informed about the nature of the study protocol, and their signed informed consent was obtained. A total of 20 subjects ( 9 male and 11 female, aged 21 to 23 years, mean age: $22.5 \pm 0.8$ years) were included in the study.

\section{Study Design}

This was a split-mouth, parallel design, double-masked, placebo-controlled study comparing $0.12 \%$ and $0.1 \%$ (plus $0.05 \%$ alcohol) $\mathrm{Chx}$ solutions and EO to sterile saline as a negative control. All subjects were systemically and periodontally healthy never-smoker dental volunteer students who had $\geq 20$ teeth. Subjects were excluded if they had decay, restorations, or any kind of prosthetic or orthodontic appliances; received antibiotic therapy during the last 6 months; or were allergic to any ingredients in the formulas. A diagram of the study design and timeline is presented in Figure 1. All study subjects underwent supragingival dental prophylaxis using ultrasonic devices (Cavitron Select SPS, Dentsply, NY, USA) 1 week prior to application of each product. They were instructed to brush using the modified Bass technique, use dental floss, and retain oral hygiene status during the 1week intervals between irrigation periods. The study design ensured that all participants served as their own controls, using four quadrants. Each participant was professionally irrigated with the two test and two control solutions. The study was completed in 41 days per subject. Baseline clinical indices of the associated quadrants were recorded on days $1,13,25$, and 37 and repeated at the end of 4-day irrigation periods with each product on the corresponding days 5, 17, 29, and 41, respectively by the main investigator (EC). Irrigation of 
the agents to the randomly assigned quadrants was accomplished by another investigator (EB). Agent-quadrant matching was randomly set up by lot (to decide the irrigation agent for each quadrant) per subject by another investigator (CK). (CK also managed all contact with the participants, ensuring all subjects completed the study with no no-shows). Subjects were banned from performing any type of oral care method-such as tooth brushing, flossing, chewing gum, using mouthrinse, etc.- during each irrigation period (i.e. between days 1 and 5, 13 and 17, 25 and 29, and 37 and 41). The mouthrinse samples were previously labelled, assigned the letters $\mathrm{A}(\mathrm{EO}), \mathrm{B}(0.12 \% \mathrm{Chx}), \mathrm{C}(0.1 \% \mathrm{Chx}$ with alcohol), and D (sterile saline). The labelling of the solutions was performed by one of the authors (SC), who was blinded to the clinical procedures. Plaque index (PI) (32), gingival index (GI) (33), periodontal probing depth (PPD), and bleeding on probing (BoP) (34) were recorded. All indexes were evaluated on all teeth, excluding third molars, in the six gingival units of the same teeth (mesio-vestibule, mid-vestibule, disto-vestibule, mesio-lingual, mid-lingual, and disto-lingual).

\section{Supragingival irrigation}

The subjects were instructed not to eat or drink anything before and 1 hour after each irrigation cycle. Four quadrants of each subject were randomly assigned for application of three test rinses $\left(0.12 \% \mathrm{Chx}-\mathrm{Klorheks}^{\circledR}, 0.1 \% \mathrm{Chx}\right.$ - Eludril ${ }^{\circledR}$, EO - Listerine ${ }^{\circledR}$ Total Care) and one negative control (sterile saline) agent as mentioned previously. The solution codes were not available to the investigators in charge of the clinical procedures until the data were completely analysed by the statistician. The previously labelled irrigation solutions were applied using blunt-tipped 5-cc injectors from a $2-3-\mathrm{cm}$ distance with a $90^{\circ}$ bevel to the tooth surfaces for 10 seconds on each tooth. As a result, each tooth was irrigated with $5 \mathrm{ml}$ of product (a total of $50 \mathrm{ml}$ solution for each tooth). The isolation of the other sites was ensured 
using custom-made imperforate acrylic stents. Supragingival irrigations were repeated on first, second, third, and fourth days of each irrigation period. On the fifth day of each irrigation period, the study participants were also asked to complete surveys that included questions to evaluate the associated solution in terms of flavour, odour, taste modification, mucosal burning, and staining.

\section{Data Analysis}

Twenty-three subjects were enrolled in the study; however, 3 subjects could not abstain from brushing. The data for 20 subjects were analysed. The primary outcome variable was plaque accumulation prevention. Other variables tested were gingival inflammation, sulcus bleeding, probing depth, and side effects (tooth stain, flavour, taste modification, mucosal burning, and so on). All variables were tested for the four irrigation solutions (three test solutions and one negative control), which were applied to each of the quadrants randomly for $1-5$ days. The Shapiro-Wilks test was used to analyse the distribution of the data. The Wilcoxon signedrank test was used for intra-group analyses of GI and BoP, which were not distributed normally. The paired samples test was used for intragroup analyses of PI and PD, which were distributed normally. ANOVA was used for inter-group analyses at 1 and 5 days. The Bonferroni correction was used for inter-group post hoc analyses. To order the agents according to their efficacy in terms of preventing plaque accumulation, the difference between days 5 and 1 for each agent was compared inter-group using ANOVA. A post hoc test (Bonferroni correction) was also used for this comparison. $\mathrm{P}<0.05$ was accepted as indicative of statistical significance. The IBM SPSS Statistics, version 21 statistical software was used for analysis. 


\section{RESULTS}

A total of 20 subjects completed the study. Demographic features are shown in Table 1. All patients were treated with full supragingival prophylaxis prior to the study. No subjects reported any complications or unexpected complaints. A total of 20 quadrants were supragingivally irrigated with each agent, and 840 sites per agent were evaluated. Table 2 shows the clinical periodontal changes before and 4 days after supragingival irrigation and a comparison of baseline and post-irrigation scores of these parameters (PI, GI, BOP, PPD) versus the control agent. Plaque scores were significantly increased in all quadrants as a result of the cessation of mechanical plaque control, irrespective of the content of the agent, despite daily professional irrigation $(\mathrm{p}<0.05)$. There was no difference at 5 days compared to 1 day of professional irrigation at any quadrant irrigated with $\mathrm{EO}, 0.12 \% \mathrm{Chx}$, or $0.1 \% \mathrm{Chx}$ in terms of GI. However, there was a significant increase in GI in the sites to which saline was applied compared to the first day of the irrigation period, as early evidence of clinical gingivitis.

Although there was an increase in the mean BoP score for all four quadrants, this increase did not reach significance $(\mathrm{p}>0.05)$. PD values did not change significantly throughout the study for any agent, despite the slight increase in quadrants to which EO, $0.12 \% \mathrm{Chx}$, and $0.1 \% \mathrm{Chx}$ had been applied.

Inter-group comparisons of all agents used in the study are also shown in Table 2. We observed significantly less plaque accumulation in the quadrants that were professionally irrigated with $0.12 \% \mathrm{Chx}$ and $0.1 \% \mathrm{Chx}$ compared to the mean $\mathrm{PI}$ in saline-irrigated quadrants. Moreover, quadrants to which EO was applied had significantly higher PI compared to those receiving $0.12 \% \mathrm{Chx}$ at 5 days post-irrigation. However, there was no difference between sites to which EO and saline were applied in terms of PI at 5 days (Figure 2). Quadrants to which $0.12 \%$ Chx were applied had significantly lower GI compared to 
quadrants irrigated with saline at 5 days post-irrigation $(\mathrm{p}<0.05)$. After the results were adjusted for Bonferroni correction, a difference between quadrants receiving saline and those receiving Chx remained evident (regardless of Chx concentration and alcohol addition).

The elevations in PI and GI scores among the agents from 1 to 5 day were evaluated (Table 3). Similar to the comparisons at 5 days, quadrants to which $0.12 \% \mathrm{Chx}$ and $0.1 \% \mathrm{Chx}$ were applied had significantly lower PI scores compared to quadrants irrigated with saline (p $<0.001)$. The mean differences between 1 and 5 days were as follows: $0.80 \pm 0.50,0.40 \pm$ $0.44,0.55 \pm 0.38$, and $1.07 \pm 0.59$ for $\mathrm{EO}, 0.12 \% \mathrm{Chx}, 0.1 \% \mathrm{Chx}$, and saline, respectively. O.12\% Chx yielded to the least change in GI as compared to saline $(\mathrm{p}<0.001)$ [Figure 3]. The results of the survey indicated that $0.1 \% \mathrm{Chx}$ with alcohol was less tolerable in terms of taste, odour and burning feeling, and EO was the agent most easily tolerated by the subjects.

\section{DISCUSSION}

The present study was designed to compare the plaque-inhibiting efficacy of three different antiplaque mouthrinses over placebo when used as a supragingival irrigation agent and their ability to prevent a possible gingivitis lesion during a 4-day non-brushing model. The nonbrushing period was set to 4 days to prevent the possibility of established lesions; however, the period was long enough so that clinically visible changes could be distinguished, as has been shown in previous studies (35-37).

Pathologic changes in gingivitis are associated with the presence of oral microorganisms in the gingival sulcus. These microorganisms are capable of synthesising products that damage epithelial and connective tissue cells as well as constituents of these tissues. The sequence of events in the development of gingivitis involves three stages. The earliest stage is the 'initial lesion', which occurs during the first 2 to 4 days after plaque has 
been allowed to accumulate. However, this initial response of the gingiva to bacterial plaque is not clinically apparent, and this stage can be termed 'subclinical gingivitis'. Beginning from the fourth day of plaque accumulation, an early lesion starts, and bleeding on probing may be evident to discriminate clinically visible gingivitis. The duration of this study was limited to 4 days, which is in the period of the initial lesion before the early lesion starts, still allowing the earliest signs of gingivitis to be clinically present (38).

Plaque is the first and main requirement for the initiation of gingivitis. To prevent gingivitis lesions, bacterial plaque must be effectively removed from tooth surfaces at least once every 48 hours (39). Mechanical plaque removal sometimes must be assisted by chemical agents. Chx and EO are the most common agents prescribed for this purpose. Both anti-plaque agents have been evaluated as adjuncts to normal oral hygiene measures $(4,21$, $23,40)$ for 3 or more months or 6 or fewer week (41). All of these studies suggest Chx to be a significantly superior supplement to normal oral hygiene measures than EO in terms of PI scores, with the exception of Axelsson and Lindhe (4), who reported similar PI scores. These studies have also reported that these two agents were comparable in their ability to prevent gingivitis. When Chx and EO were compared in non-brushing models, the duration of the study was limited to 2 weeks or less $(22,42-44)$. These short-term studies also report that Chx was significantly superior in terms of preventing de novo plaque formation. When the overall data from all these studies are considered, it can be suggested that $\mathrm{Chx}$ has superior antiplaque effects than EO. However, there is variety in these studies in terms of the concentration of Chx (ranging from $0.1 \%$ to $0.12 \%$ and $0.2 \%$ ), presence of alcohol in the formulations, and the content of the placebo formulation (saline, hydro-alcohol solution, sterile water, etc.). In the present study, two concentrations of Chx $(0.1 \%$ and $0.12 \%)$ were used to evaluate the effect of the concentration of the formulation on the efficacy of the agent. $0.12 \% \mathrm{Chx}$ presented anti-plaque effects superior to those of $0.1 \% \mathrm{Chx}$, despite the 
fact that the latter formulation contained alcohol. Alcohol below $10 \%$ has been reported to have almost no effect on biofilm growth (45). Therefore, the superior antiplaque effects of $0.12 \%$ Chx over $0.1 \%$ Chx are likely the result of the difference in concentration between the two formulations. Few studies compare the concentrations of Chx used in the current study. Among these, Olsson et al. (46) reported similar antiplaque effects of concentrations of $0.12 \%$ and $0.1 \%$. In contrast, Addy et al. found $0.12 \% \mathrm{Chx}$ to lead to significantly lower plaque scores at 19 days compared to $0.1 \% \mathrm{Chx}(47)$. The results of the current study suggest that the benefits of alcohol supplementation in the formulation of mouthrinses are less than the benefits of a slightly increased Chx concentration. By this strategy, the possible side effects of alcohol can be bypassed.

PI was significantly increased at 5 days in all sites regardless of the irrigation solution used. In this respect, the maturity of the plaque might be a determining factor, in that mature plaque cannot be removed by supragingival irrigation or rinsing, and these agents cannot replace mechanical plaque removal and should be used only as an adjunct to regular oral hygiene measures. However, the least amount of plaque after ceasing regular oral hygiene measures was observed in the quadrants irrigated using $0.12 \% \mathrm{Chx}$. In this study, alcohol-free $0.12 \% \mathrm{Chx}$ was superior to $0.1 \% \mathrm{Chx}$ with alcohol. No difference was observed between EO ( $22 \%$ alcohol in the formulation) and saline, which was the negative control. Likewise, the least marked gingival changes as assessed by GI were observed in the quadrants irrigated with $0.12 \%$ Chx. Statistically significant changes compared to baseline were observed only in quadrants irrigated with the negative control, saline, possibly validating the protective effects of all three test agents against development of gingivitis during the first 4 days of plaque accumulation. Still, a significant difference existed only between $0.12 \% \mathrm{Chx}$ and saline at the end of the study, confirming $0.12 \% \mathrm{Chx}$ to be the most effective agent in terms of preventing gingival inflammation. 
Most studies designed to evaluate the efficiency of mouthrinses highlight PI scores (4, $7,9,13,21,31,37)$. GI is important for determining the actual efficacy because the rationale for inhibiting plaque accumulation is preventing plaque-related disease, mainly gingivitis. According to the specific-plaque hypothesis, the species composition of the plaque, rather than the amount of plaque, is responsible for gingival disease. When gingival inflammation is set as a primary outcome variable, the results of the current study indicate that all test agents are effective in terms of prevent signs of gingivitis. Only sites to which saline was applied showed statistically significant GI scores at the fifth day compared to the first day. All test agents succeeded in preventing significant gingival index changes; however, only $0.12 \% \mathrm{Chx}$ resulted in baseline GI scores being retained, in contrast to the slightly higher scores with the other test agents. However, in a recent systematic review that included long-term studies $(\geq 4$ weeks), the authors concluded that although EO mouthrinses were less effective for plaque

control, there were no marked differences in the control of gingival inflammation compared to chlorhexidine (48).

Chx as a mouthrinse can cause local side effects, including taste disturbance; staining of teeth, tongue and restorations; and enhanced supragingival calculus formation $(37,49,50)$. In the current study, no side effects related to the agents were observed, probably due to the short duration of the study.

\section{CONCLUSION}

The results of the present study suggest that $\mathrm{Chx}$ at a $0.12 \%$ concentration has superior antiplaque and anti-gingivitis effects compared to $0.1 \% \mathrm{Chx}$ and EO in a 4-day non-brushing model. However, further studies with larger sample sizes are needed.

\section{Conflicts of interest}

The authors have no conflicts of interest relevant to this study. 


\section{REFERENCES}

1. Scannapieco FA, Levine MJ. Saliva and dental pellicles. In: Genco RJ, Goldman HM, Cohen DW. Contemporary Periodontics. St Louis: Mosby:1990.

2. Chambrone LA, Chambrone L. Results of a 20-year oral hygiene and prevention programme on caries and periodontal disease in children attended at a private periodontal practice. Int J Dent Hyg, 2011, 2:155-8.

3. Wolff LF. Chemotherapeutic agents in the prevention and treatment of periodontal disease. Northwest Dent. 1985;6:15-24. Review.

4. Axelsson P, Lindhe J. Efficacy of mouthrinses in inhibiting dental plaque and gingivitis in man. J Clin Periodontol. 1987;14:205-12.

5. Bouwsma OJ. The status, future, and problems of oral antiseptics. Curr Opin Periodontol. 1996;3:78-84. Review.

6. Löe H, Schiott CR. The effect of mouthrinses and topical application of chlorhexidine on the development of dental plaque and gingivitis in man. Journal of Periodontal Research, 1970,5,79-83.

7. Van Strydonck DA, Timmerman MF, van der Velden U, van der Weijden GA.Plaque inhibition of two commercially available chlorhexidine mouthrinses. J Clin Periodontol. 2005 Mar;32(3):305-9.

8. Jones CG. Chlorhexidine: is it still the gold standard? Periodontol 2000. 1997 Oct; 15:55-62.

9. Berchier CE, Slot DE, Van der Weijden GA.The efficacy of $0.12 \%$ chlorhexidine mouthrinse compared with $0.2 \%$ on plaque accumulation and periodontal parameters: a systematic review. J Clin Periodontol. 2010 Sep;37(9):829-39. doi: 10.1111/j.1600051X.2010.01575.x. Epub 2010 Jul 7. 
10. Lang NP, Hotz P, Graf H, Geering AH, Saxer UP, Sturzenberger OP, Meckel AH. Effects of supervised chlorhexidine mouthrinses in children. A longitudinal clinical trial. J Periodontal Res. 1982 Jan;17(1):101-11.

11. Segreto VA, Collins EM, Beiswanger BB, de la Rosa M, Issacs RL, Lang NR et al. A comparison of mouthrinses containing two concentrations of chlorhexidine. J Periodontal Res. 1986;21(16):23-32.

12. Keijser JA, Verkade H, Timmerman MF, Van der Weijden FA. Comparison of 2 commercially available chlorhexidine mouthrinses. J Periodontol. 2003 Feb;74(2):214-8.

13. Marchetti E, Mummolo S, Di Mattia J, Casalena F, Di Martino S, Mattei A, Marzo G. Efficacy of essential oil mouthwash with and without alcohol: a 3-day plaque accumulation model. Trials. 2011 Dec 15;12:262. doi: 10.1186/1745-6215-12-262.

14. Addy M. Chlorhexidine compared with other locally delivered antimicrobials. A short review. J Clin Periodontol 1986; 13: 957-964.

15. Ernst CP, Prockl K, Willershausen B. The effectiveness and side effects of $0.1 \%$ and 0.2\% chlorhexidine mouthrinses: a clinical study. Quintessence Int. 1998 Jul;29(7):443-8.

16. Vigeant P, Loo VG, Bertrand C, Dixon C, Hollis R, Pfaller MA, McLean AP, Briedis DJ, Perl TM, Robson HG. An outbreak of Serratia marcescens infections related to contaminated chlorhexidine. Infect Control Hosp Epidemiol. 1998;19:791-4.

17. Elmore JG, Horwitz RI. Oral cancer and mouthwash use: evaluation of the epidemiologic evidence. Otolaryngol Head Neck Surg. 1995;113:253-61. Review.

18. Shapiro S, Castellana JV, Sprafka JM. Alcohol-containing mouthwashes and oropharyngeal cancer: a spurious association due to underascertainment of confounders? Am J Epidemiol. 1996 Dec 15;144(12):1091-5. Review. 
19. Eldridge KR, Finnie SF, Stephens JA, Mauad AM, Munoz CA, Kettering JD. Efficacy of an alcohol-free chlorhexidine mouthrinse as an antimicrobial agent. J Prosthet Dent. 1998;80:685-90.

20. Overra D, Roldán S, Santacruz I, Santos S, Masdevall M, Sanz M. Differences in antimicrobial activity of four commercial $0.12 \%$ chlorhexidine mouthrinse formulations: an in vitro contact test and salivary bacterial counts study. J Clin Periodontol. 2003;30:307-14.

21. Overholser CD, Meiller TF, DePaola LG, Minah GE, Niehaus C. Comparative effects of 2 chemotherapeutic mouthrinses on the development of supragingival dental plaque and gingivitis. J Clin Periodontol 1990; 17:575-579.

22. Moran J, Addy M, Kohut B, Hovliaras CA, Newcombe RG. Efficacy of mouthrinses in inhibiting the development of supragingival plaque over a 4-day period of no oral hygiene. J Periodontol 1994;65:904-907.

23. Charles C, Sharma N, Galustians C, Qaqish HJ, McGuire JA, Vincent JW. Comparative efficacy of an antiseptic mouthrinse and an antiplaque/antigingivitis dentifrice. A six-month clinical trial. J Am Dent Assoc 2001;132:670-675.

24. Rosin M, Welk A, Kocher T, Majic-Todt A, Kramer A, Pitten FA.The effect of a polyhexamethylene biguanide mouthrinse compared to an essential oil rinse and a chlorhexidine rinse on bacterial counts and 4-day plaque regrowth. J Clin Periodontol. 2002 May;29(5):392-9.

25. Riep BG, Bernimoulin JP, Barnett ML. Comparative antiplaque effectiveness of an essential oil and an amine fluoride/stannous fluoride mouthrinse. J Clin Periodontol $1999 ; 26: 164-168$ 
26. Eick S, Goltz S, Nietzsche S, Jentsch H, Pfister W. Efficacy of chlorhexidine digluconate-containing formulations and other mouthrinses against periodontopathogenic microorganisms. Quintessence Int. 2011;42:687-700.

27. Chen Y, Wong RW, Seneviratne CJ, Hägg U, McGrath C, Samaranayake LP. Comparison of the antimicrobial activity of Listerine and Corsodyl on orthodontic brackets in vitro. Am J Orthod Dentofacial Orthop. 2011;140:537-42.

28. Gunsolley JC. Clinical efficacy of antimicrobial mouthrinses. J Dent. 2010;38: 6-10.

29. Feng HS, Bernardo CC, Sonoda LL, Hayashi F, Romito GA, De Lima LA, Lotufo RF, Pannuti CM. Subgingival ultrasonic instrumentation of residual pockets irrigated with essential oils: a randomized controlled trial. J Clin Periodontol. 2011;38:637-43.

30. McKenzie WT, Forgas L, Vernino AR, Parker D, Limestall JD. Comparison of a $0.12 \%$ chlorhexidine mouthrinse and an essential oils mouthrinse on oral health in institutionalized, mentally handicapped adults: one-year results. J Periodontol. 1992;63:187-93.

31. Neely AL. Essential oils mouthwash (EOMW) may be equivalent to chlorhexidine (CHX) for long-term control of gingival inflammation but $\mathrm{CHX}$ appears to perform better than EOMW in plaque control. J Evid Based Dent Pract. 2012;12(3):69-72.

32. Silness J, Loe H. Periodontal Disease In Pregnancy. II. Correlation Between Oral Hygiene And Periodontal Condition. Acta Odontol Scand. 1964;22:121-35.

33. Löe H, Silness J. Periodontal Disease In Pregnancy. I. Prevalence And Severity. Acta Odontol Scand. 1963;21:533-51.

34. Ainamo J, Bay I. Problems and proposals for recording gingivitis and plaque. Int Dent J. 1975 Dec;25(4):229-35. 
35. Arweiler NB, Boehnke N, Sculean A, Hellwig E, Auschill TM. Differences in efficacy of two commercial $0.2 \%$ chlorhexidine mouthrinse solutions: a 4 -day plaque re-growth study. J Clin Periodontol. 2006 May;33(5):334-9.

36. Pizzo G, La Cara M, Licata ME, Pizzo I, D'Angelo M. The effects of an essential oil and an amine fluoride/stannous fluoride mouthrinse on supragingival plaque regrowth. J Periodontol. 2008 Jul;79(7):1177-83. doi: 10.1902/jop.2008.070583.

37. Pilloni A, Zeza B, Mongardini C, Dominici F, Cassini MA, Polimeni A. A preliminary comparison of the effect of $0.3 \%$ versus $0.2 \%$ chlorhexidine mouth rinse on de novo plaque formation: a monocentre randomized double-blind crossover trial. Int J Dent Hyg. 2013 Aug;11(3):198-202. doi: 10.1111/idh.12007. Epub 2013 Jan 16.

38. Preshaw PM. Periodontal Pathogenesis In: Newman MG, Takei H, Klokkevold PR \& Carranza FA, eds. Carranza's Clinical Periodontology, 12th ed. St. Louis, Missouri Elsevier, Saunders, 2015: 76 - 100

39. Lang NP, Cumming BR, Löe H. Toothbrushing frequency as it relates to plaque development and gingival health. J Periodontol. 1973 Jul;44(7):396-405.

40. Haffajee AD, Roberts C, Murray L, Veiga N, Martin L, Teles RP, Letteri M, Socransky SS. Effect of herbal, essential oils, and chlorhexidine mouthrinses on the composition of the subgingival microbiota and clinical periodontal parameters. J Clin Dent. 2009;20:211-7.

41. Brecx M, Netuschil L, Reichert B, Schreil G. Efficacy of Listerine, Meridol and chlorhexidine mouthrinses on plaque, gingivitis and plaque bacteria vitality. J Clin Periodontol 1990; 17:292-7.

42. Maruniak J, Clark WB, Walker CB, Magnusson I, Marks RG, Taylor M, et al. The effect of 3 mouthrinses on plaque and gingivitis development. J Clin Periodontol 1992;19: 19-23. 
43. Ramberg P, Furuichi Y, Lindhe J, Gaffar A. A model for studying the effects of mouthrinses on de novo plaque formation. J Clin Periodontol. 1992 Aug;19(7):50920.

44. Preus HR, Koldsland OC, Aass AM, Sandvik L, Hansen BF The plaque- and gingivitis-inhibiting capacity of a commercially available essential oil product. A parallel, split-mouth, single blind, randomized, placebo-controlled clinical study. Acta Odontol Scand. 2013 Nov;71(6):1613-9. doi: 10.3109/00016357.2013.782506. Epub 2013 May 3.

45. Sissons CH, Wong L, Cutress TW. Inhibition by ethanol of the growth of biofilm and dispersed microcosm dental plaques. Arch Oral Biol. 1996 Jan;41(1):27-34.

46. Olsson H, Asklöw B, Johansson E, Slotte C. Rinsing with alcohol-free or alcoholbased chlorhexidine solutions after periodontal surgery. A double-blind, randomized, cross-over, pilot study. Swed Dent J. 2012;36:91-9.

47. Addy M, Moran J, Newcombe R. A comparison of $0.12 \%$ and $0.1 \%$ chlorhexidine mouthrinses on the development of plaque and gingivitis. Clin Prev Dent. 1991 MayJun;13(3):26-9.

48. Van Leeuwen MP, Slot DE, Van der Weijden GA: Essential oils compared to chlorhexidine with respect to plaque and parameters of gingival inflammation: a systematic review. J Periodontology 2011, 82:174-194.

49. Addy M. The use of antiseptics in periodontal therapy. In: Lindhe J, Karring T, Lang NP, eds. Clinical Periodontology and Implant Dentistry, 4th ed. Copenhagen: Blackwell Munksgaard; 2003: 464-493.

50. Santos A. Evidence-based control of plaque and gingivitis. J Clin Periodontol 2003; 30 (Suppl. 5):13-16. 
Table 1: Demographic features of the study participants

\begin{tabular}{ll}
\hline Mean Age \pm SD & $22.55 \pm 0.82$ \\
\hline Range & $21-23$ \\
\hline Gender (female / male) & $11 / 9$ \\
\hline Smokers & None \\
\hline
\end{tabular}

Table 2: Inter-group and Intra-group Comparisons of the Agents in Terms of Clinical Parameters (mean \pm sd)

\begin{tabular}{|c|c|c|c|c|c|}
\hline $\begin{array}{l}\text { Periodontal } \\
\text { Parameters }\end{array}$ & $\begin{array}{l}\text { Time } \\
\text { Point }\end{array}$ & $\mathrm{EO}$ & $0.12 \% \mathrm{CHX}$ & $0.1 \% \mathrm{CHX}$ & Saline \\
\hline \multirow[t]{2}{*}{ PI } & $1^{\text {st }}$ day & $0.17 \pm 0.16$ & $0.17 \pm 0.17$ & $0.24 \pm 0.21$ & $0.22 \pm 0.20$ \\
\hline & $5^{\text {th }}$ day & $0.97 \pm 0.46^{\text {ब\# }}$ & $0.58 \pm 0.37^{* * *}$ & $0.80 \pm 0.33^{* * *}$ & $1.30 \pm 0.55^{*}$ \\
\hline \multirow[t]{2}{*}{ GI } & $1^{\text {st }}$ day & $0.09 \pm 0.10$ & $0.11 \pm 0.15$ & $0.09 \pm 0.12$ & $0.10 \pm 0.10$ \\
\hline & $5^{\text {th }}$ day & $0.11 \pm 0.12$ & $0.11 \pm 0.13^{* *}$ & $0.12 \pm 0.13$ & $0.22 \pm 0.17^{\text {ศी }}$ \\
\hline \multirow[t]{2}{*}{$\mathrm{BoP}$} & $1^{\text {st }}$ day & $0.12 \pm 0.16$ & $0.13 \pm 0.16$ & $0.13 \pm 0.09$ & $0.15 \pm 0.11$ \\
\hline & $5^{\text {th }}$ day & $0.16 \pm 0.11$ & $0.18 \pm 0.13$ & $0.20 \pm 0.16$ & $0.27 \pm 0.14$ \\
\hline \multirow[t]{2}{*}{ PPD } & $1^{\text {st }}$ day & $1.65 \pm 0.17$ & $1.67 \pm 0.15$ & $0.60 \pm 0.22$ & $1.65 \pm 0.22$ \\
\hline & $5^{\text {th }}$ day & $1.70 \pm 0.25$ & $1.69 \pm 0.23$ & $1.59 \pm 0.26$ & $1.63 \pm 0.27$ \\
\hline
\end{tabular}

Paired samples $t$ test, Wilcoxon Signed rank test, ANOVA, Bonferroni correction.

No difference between baseline levels of PI, GI, BoP and PD among the agents.

No difference between 5 days levels of BoP and PD among the agents.

*: significantly different compared to baseline $(\mathrm{p}=0.000)$

T: significantly different compared to baseline $(\mathrm{p}=0.001)$

ๆף: significantly different compared to baseline $(\mathrm{p}=0.002)$

**:significant difference compared to saline $(\mathrm{p}<0.001)$

\#: significantly different compared to $0.12 \%$ chlorhexidine

PI: Plaque index,

GI: Gingival index,

BoP: Bleeding on probing,

PPD: Periodontal probing depth 
Table 3: Mean \pm SD Elevation in PI and GI from 1 day to 5 day

\begin{tabular}{cccccc}
\hline Variables & EO & $0.12 \%$ CHX & $0.1 \%$ CHX & Saline & $\mathrm{p}$ \\
\hline PI & $0.80 \pm 0.51$ & $0.41 \pm 0.44^{*}$ & $0.55 \pm 0.38^{*}$ & $1.07 \pm 0.59$ & $<0.001$ \\
GI & $0.03 \pm 0.10$ & $0.00 \pm 0.15^{*}$ & $0.028 \pm 0.16$ & $0.12 \pm 0.14$ & $<0.001$ \\
\hline
\end{tabular}

ANOVA, Bonferroni correction

*: significantly different compared to saline

PI: Plaque index,

GI: gingival index,

BoP: bleeding on probing,

PPD: periodontal probing depth 


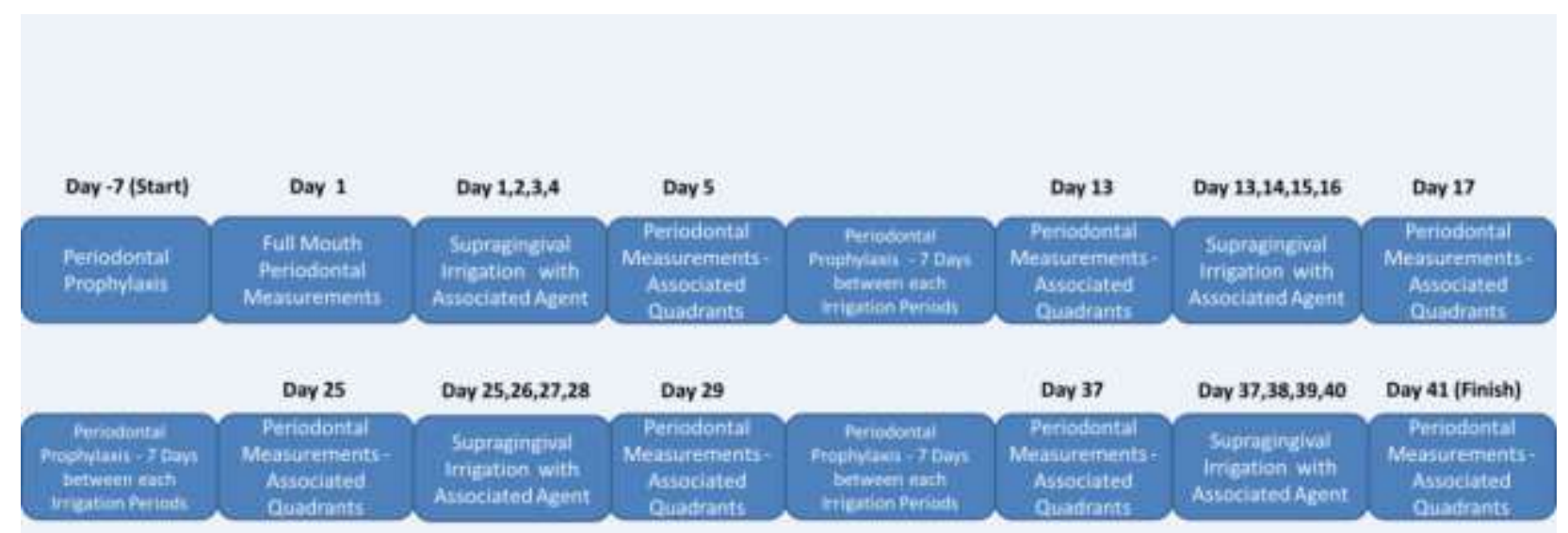

Figure 1

Fig 1: Diagram of the study timeline.

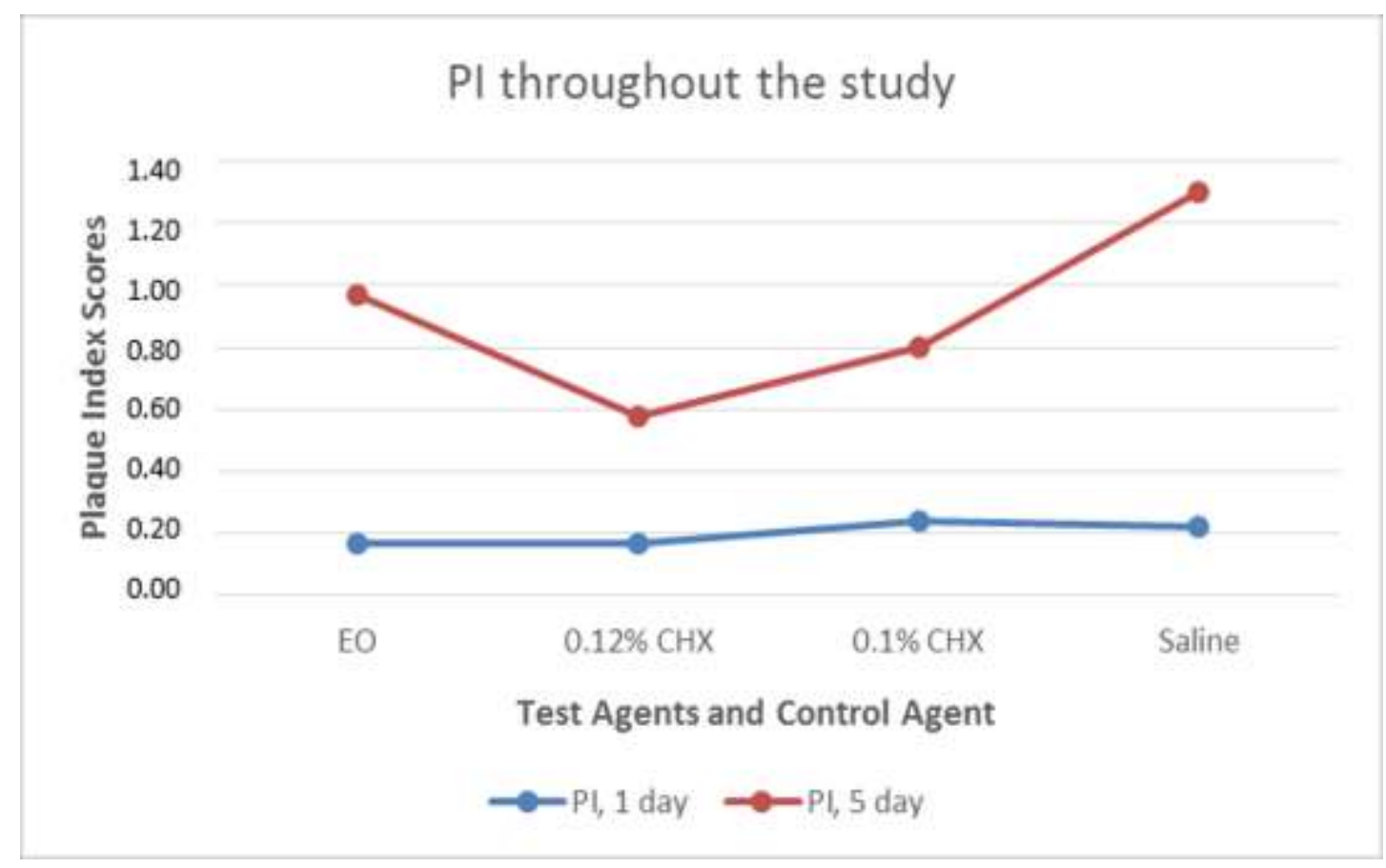

Fig 2: Inter-group and Intra-group Comparisons of the Agents in Terms of PI 


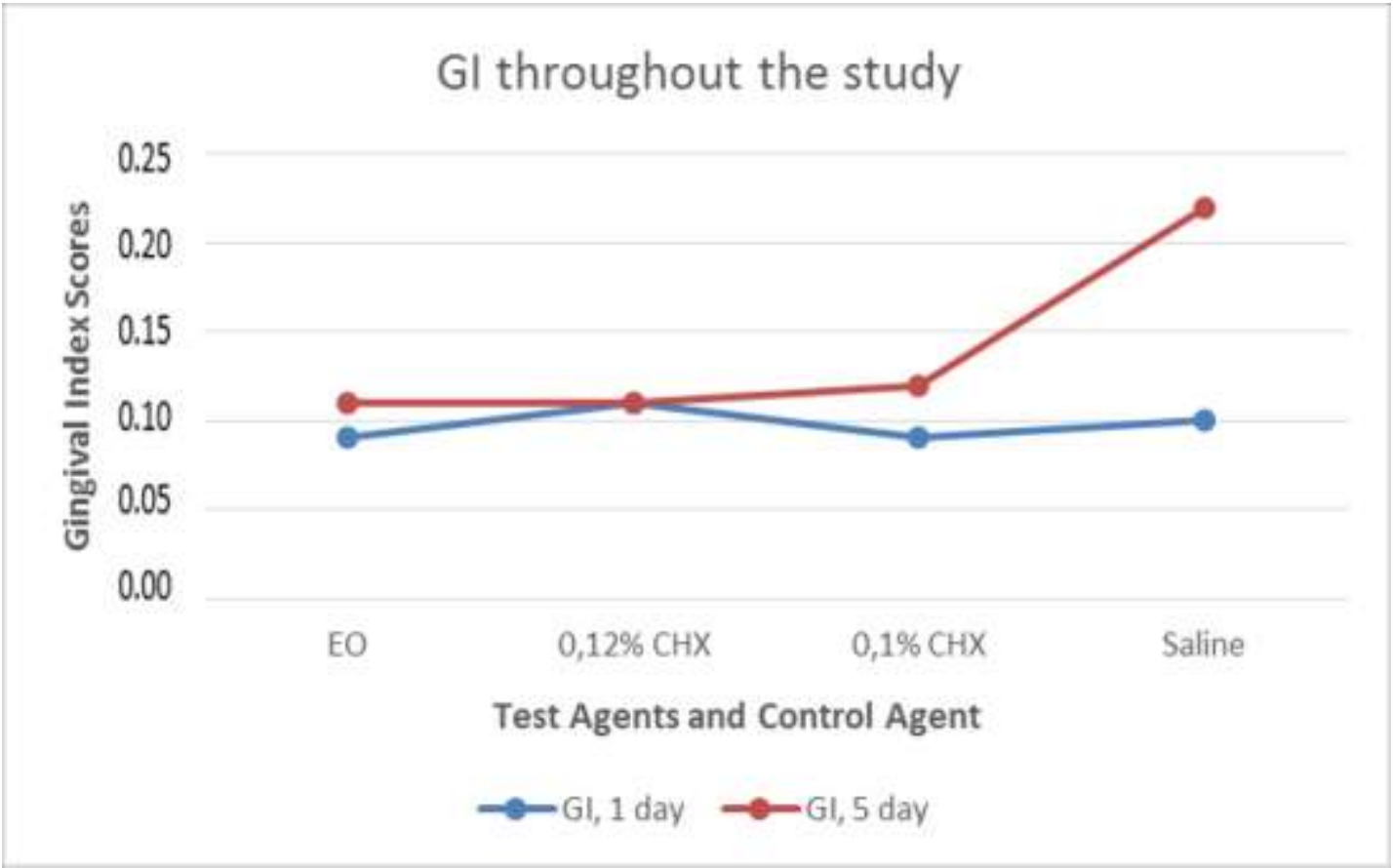

Fig 3: Inter-group and Intra-group Comparisons of the Agents in Terms of GI 